\title{
Efeito de Dietas Simples e Complexas sobre a Morfo-fisiologia Gastrintestinal de Leitões até 35 Dias de Idade $^{1}$
}

\author{
Alexandre de Oliveira Teixeira ${ }^{2}$, Darci Clementino Lopes $^{3}$, Aloízio Soares Ferreira ${ }^{3}$, Juarez \\ Lopes Donzele ${ }^{3}$, Izabel Regina S. Costa ${ }^{4}$, Rita Flávia Miranda de Oliveira ${ }^{3}$, Vanusa Patrícia de \\ Araújo Ferreira ${ }^{5}$, André Viana C. de Souza ${ }^{2}$
}

\begin{abstract}
RESUMO - Um experimento foi realizado com o objetivo de verificar o efeito de dietas simples e complexas sobre a morfo-fisiologia gastrintestinal de leitões, nas fases de maternidade ( 7 aos 21 dias) e pós-desmame (21 aos 35 dias de idade). Utilizaram-se 96 leitões mestiços (machos e fêmeas), distribuídos em delineamento de blocos casualizados, com quatro tratamentos, seis repetições e quatro leitões por unidade experimental. As dietas usadas foram: duas simples - uma com 16 e a outra $19 \%$ de proteína (PB) - e duas complexas - uma à base de milho, farinha de peixe, leite em pó e glúten de milho, sem o uso de farelo de soja (CSFS), e a outra à base de milho, farinha de peixe, leite em pó, farelo de soja e sem glúten de milho (CCFS), ambas com 19\% de PB. Os leitões foram abatidos aos $14,21,28$ e 35 dias de idade. Houve redução dos pesos absoluto e relativo do fígado e do peso relativo do pâncreas, com a utilização da dieta CSFS. $\mathrm{O}$ pH da ingesta estomacal e da digesta intestinal não foi influenciado pelo tipo de dieta. Os animais que consumiram a dieta simples com 16\% de PB e complexa CSFS obtiveram maior profundidade de cripta (PC) aos 21 e 35 dias de idade, respectivamente, não tendo efeito sobre a altura das vilosidades (AV) e relação vilosidade:cripta (RVC). A PC aumentou linearmente, enquanto a AV e RVC diminuíram quadraticamente até 27 e 30 dias de idade, respectivamente. As dietas simples ou complexa, em razão da qualidade e quantidade dos ingredientes, afetaram a profundidade das criptas do intestino delgado e o peso dos órgãos auxiliares da digestão, mas não influenciaram o pH do conteúdo estomacal e intestinal de leitões desmamados aos 21 dias de idade.
\end{abstract}

Palavras-chave: desmame, histologia, intestino, leitão, nutrição, $\mathrm{pH}$

\section{Effect of Simple and Complex Diets on the Morpho-Physiologycal Gastrointestinal of Young Pigs at 35 Days of Age}

ABSTRACT - An experiment was conducted with objective to evaluate the effect of the simple and complex diets on the morphofisiologycal gastrointestinal of young pigs, on their pre nursery ( $7^{\text {th }}$ to $21^{\text {st }}$ day) and nursery phases $\left(21^{\text {st }}\right.$ to $35^{\text {nd }}$ of age). Ninety six crossbreed young pigs (male and females) were allotted to a randomized block design with four treatments, six replications and four young pigs for each experimental unit. It were used diets: two simple; a with 16 and the other with 19\% the protein (CP) and two complex; a to the base corn, fish meal, dried milk, corn gluten without the use of soybean meal (CSFS) and the other to the base corn, fish meal, dried milk, soybean meal, without the use of corn gluten (CCFS), both with $19 \%$ the CP. The pigs were slaughtered at $14,21,28$ and 35 days of age. There was reduction of liver absolute and relative weights and of pancreas relative weights, by using CSFS diet. pH of the stomach and intestine contents was not influenced by the diet. The animals fed simple diet with $16 \%$ of CP and complex CSFS showed larger crypt depth (CD) at 21 and 35 days of age, respectively, but did not show effect on the villous height (VH) and villous:crypt relation (VCR). CD it increased linearly, while VH and RVC decreased quadraticly until $27^{\text {th }}$ and $30^{\text {th }}$ days of age, respectively. The simple or complex diet, concerning quality and quantity of ingredients, affected the crypts depth of the small intestine and the auxiliary organs weight of the digestion, but did not affect the stomachal $\mathrm{pH}$ and intestine contents of pigs weaned at 21 days of age.

Key Words: histology, intestine, nutrition, $\mathrm{pH}$, young pig, weaning

\section{Introdução}

As dietas pré e pós-desmame têm sido freqüentemente estudadas, à medida que diminui a idade ao desmame, a fim de assegurar taxa ótima de crescimento. Todavia, o consumo de ração nessas fases é pequeno e variável, sendo insuficiente para atender as exigências de mantença dos leitões (Pluske et al., 1995).

O uso de dietas complexas com alta porcentagem de produtos lácteos, associados a fonte protéicas de origem animal e vegetal, baseia-se na melhoria da digestibilidade e no aumento dos níveis de ingestão de

\footnotetext{
1 Projeto financiado pela FAPEMIG.

2 Zootecnistas e doutores em Zootecnia - UFV - Viçosa - MG - CEP: 36.571-000. E.mail: teixeira@alunos.ufv.br

3 Professores do Departamento de Zootecnia - UFV - Viçosa - MG - CEP: 36.571-000.

${ }^{4}$ Professora do Departamento de Biologia Geral - UFV - Viçosa - MG - CEP: 36.571-000.

5 Professora da FEAD - Belo Horizonte - MG.
} 
ração, sem predispor o leitão a problemas digestivos. Por outro lado, a utilização de rações simples diminui os custos e facilita o manejo da alimentação (Nelssen et al. 1997).

Berto et al. (1996), estudando o fornecimento de dietas simples e complexas na fase inicial de leitões desmamados aos 28 dias de idade, não encontraram diferença sobre espessura da mucosa, altura das vilosidades e coeficientes de digestibilidade da matéria seca, proteína bruta e energia digestível e metabolizável. Berto et al. (1997) observaram que dietas simples adequadamente formuladas proporcionaram desempenho semelhante, ao obtido com as complexas, independentemente do sistema de alimentação e sem reflexo negativo no desempenho dos leitões nas fases de crescimento e terminação.

Mascarenhas et al. (1999) verificaram que dietas simples ou complexas, com $19 \%$ de proteína, proporcionaram desempenho semelhante, constatando que a diminuição do teor de proteína (16\%) em rações simples e a presença de glúten de milho nas rações complexas refletiram negativamente no desempenho de leitões desmamados aos 21 dias de idade, sendo insignificante o consumo diário de ração (CDR) até o desmame.

Ao desmame, o sistema digestivo de leitões passa por modificações até que esteja preparado para a digestão de ingredientes de origem vegetal. A primeira delas é o aumento na produção de enzimas pancreáticas e dos órgãos auxiliares da digestão (Makkink et al., 1994ab). A variação do pH gástrico, devido à dieta, tem importância decisiva no estado sanitário e digestivo (Wilson \& Leibholz, 1981). Segundo o autor, elevando-se o $\mathrm{pH}$, diminui-se atividade proteolítica e bactericida no estômago.

Segundo Manners et al. (1962), comparada ao leite da porca, as proteínas da soja têm maior ação tamponante no estômago do leitão e o aumento do $\mathrm{pH}$ reduz a atividade da pepsina, transferindo para o intestino delgado maior quantidade de proteínas intactas.

Sabe-se que a mucosa intestinal tem grande importância no processo absortivo e digestivo e as alterações histopatológicas estão relacionadas à imaturidade dos enterócitos, à diminuição da altura das vilosidades e ao aumento das mitoses nas criptas, do número de placas de Peyer, entre outras. Nas vilosidades, a renovação dos enterócitos pode demorar 3 a 4 dias (Moon, 1971) e, quando a proliferação das células for maior que a descamação, haverá hipertrofia da mucosa; o contrário, predispõe à atrofia.

A etiologia dessas alterações é complexa, decor- rendo de fatores como: imaturidade imunológica ( $\mathrm{Li}$ et al., 1990), substituição do leite da porca, que possui fatores intrínsecos a $\operatorname{IgA}$, fator de crescimento epidermal, poliaminas e glutamina (Pluske et al., 1997), estresse ao desmame (Berto et al., 1996), consumo das dietas (Pluske et al., 1996a). Thomaz et al. (1996) destacaram a importância das fontes protéicas da dieta; Abreu (1994), do nível de farelo de soja; Bertol et al. (1997ab), do tipo de processamento do alimento; Jin et al. (1994), do teor de fibra; Hall \& Byrne (1989), da forma física da ração, entre outros.

Avaliou-se o efeito de dietas simples e complexas, usadas nos períodos pré e pós-desmame dos leitões desmamados aos 21 dias de idade, sobre a morfo-fisilogia do trato gastrintestinal dos leitões até 35 dias de idade.

\section{Material e Métodos}

O experimento foi conduzido no Setor de Suinocultura, do Departamento de Zootecnia, do Centro de Ciências Agrárias, da Universidade Federal de Viçosa - MG, no período de maio a setembro de 1996.

Foram utilizados 96 leitões mestiços (48 machos castrados e 48 fêmeas), distribuídos em um delineamento experimental de blocos ao acaso com quatro tratamentos e seis repetições. Adotou-se como critério, na formação dos blocos, a data do parto das porcas. Utilizaram-se as seguintes instalações: maternidade ( 7 aos 21 dias de idade) e creche (21 aos 35 dias). Na maternidade, utilizaram-se 24 leitegadas uniformes, mantendo-se nove leitões por porca, com peso de 2,05 $\pm 0,573 \mathrm{~kg}$ aos sete dias. Na fase de creche, a unidade experimental foi constituída de três leitões, distribuídos em função dos tratamentos recebidos quando lactentes.

As dietas experimentais fornecidas aos leitões do sétimo ao 35 o dia de idade foram: complexa à base de milho, farinha de peixe, leite em pó e glúten de milho, com 19\% de PB (Complexa sem farelo de soja CSFS); simples à base de milho e farelo de soja, com $19 \%$ de proteína bruta (simples milho e soja - SMS); complexa à base de milho, farinha de peixe, leite em pó e farelo de soja, com 19\% de PB (complexa com farelo de soja - CCFS); simples à base de milho, farelo de soja e farelo de trigo, com $16 \%$ de PB (simples lactação - SL).

As dietas foram formuladas para atender as exigências nutricionais dos leitões, conforme recomendações de Rostagno et al. (1992), cujas compo-

R. Bras. Zootec., v.32, n.4, p.926-934, 2003 
sições centesimal e nutricional calculadas estão apresentadas na Tabela 1.

Foram consideradas dietas complexas as que continham fontes protéicas de origem animal e vegetal e simples, as que continham apenas farelo de soja como ingrediente protéico.

Os leitões foram desmamados às $14 \mathrm{~h}$, aos 21 dias de idade, fornecendo-se água e dietas sólidas à vontade. Após o desmame, os animais foram alojados em sala de creche construída em alvenaria, com piso de concreto, forro de madeira rebaixado, janelas de vidro tipo basculante, contendo gaiolas metálicas suspensas, medindo $1,60 \times 1,0 \times 0,56 \mathrm{~m}$, providas de piso em plástico expandido, laterais em tela metálica, comedouros semi-automáticos e bebedouros tipo chupeta. Durante o experimento, a ventilação e a temperatura ambiente foram efetuadas controlando-se as janelas e as lâmpadas de aquecimento sobre as gaiolas.
Aos 14, 21, 28 e 35 dias de idade, um leitão de cada unidade experimental foi selecionado aleatoriamente, pesado, abatido por sangramento e eviscerado. $\mathrm{O}$ fígado e pâncreas foram pesados e o intestino delgado, esticado e medido o comprimento. Foram feitas medições de $\mathrm{pH}$ na ingesta da região pilórica do estõmago e da região proximal do intestino delgado, coletada na região correspondente a $25 \%$ do comprimento total do intestino. A aferição do $\mathrm{pH}$ foi efetuada com peagâmetro elétrico padronizado à temperatura de $25^{\circ} \mathrm{C}$ e $95 \%$ de sensibilidade.

Amostras de $2 \mathrm{~cm}$ de comprimento foram retiradas nas regiões correspondentes a 25,50 e $75 \%$ do intestino delgado. O material foi lavado em solução fisiológica, fixado em BOUIN por 24 horas, desidratado em álcool etílico, diafanizado em xilol e incluído em parafina.

Em cada lâmina foram colocadas quatro secções com $7 \mathrm{~mm}$ de espessura. Na seleção de uma secção e

Tabela 1 - Composição percentual das dietas experimentais

Table 1 - Percentage composition of the experimental diets

\begin{tabular}{|c|c|c|c|c|}
\hline \multirow[t]{2}{*}{$\begin{array}{l}\text { Ingredientes (\%) } \\
\text { Ingredient }\end{array}$} & \multicolumn{4}{|c|}{$\begin{array}{c}\text { Dietas experimentais } \\
\text { Experimental diets }\end{array}$} \\
\hline & CSFS & SMS & CCFS & SL \\
\hline Milho (Corn) & 65,00 & 64,035 & 63,725 & 60,07 \\
\hline Farelo de soja (Soybean meal) & - & 29,00 & 17,00 & 21,00 \\
\hline Farelo de trigo (Wheat meal) & - & - & - & 10,00 \\
\hline Farinha de peixe (Fish meal) & 8,50 & - & 7,00 & - \\
\hline Leite em pó (Dried milk) & 12,00 & - & 10,00 & - \\
\hline Glúten de milho(Corn gluten) & 10,00 & - & - & - \\
\hline Açúcar (Sugarcane) & - & 2,50 & - & 2,00 \\
\hline Óleo de soja (Soybean oil) & - & 0,77 & 0,56 & 3,50 \\
\hline Calcário (Limestone) & 0,90 & 1,10 & 0,80 & 1,20 \\
\hline Fosfato bicálcico (Dicalcium phosphate) & - & 1,60 & 0,20 & 1,55 \\
\hline $\operatorname{Sal}($ Salt) & 0,40 & 0,40 & 0,40 & 0,50 \\
\hline $\mathrm{L}$ - Lisina $\mathrm{HCl}(L-$ Lysine $H C l)(78,4 \%)$ & 0,48 & 0,35 & 0,12 & - \\
\hline DL-Metionina (DL-Methionine) $(99 \%)$ & - & 0,05 & - & - \\
\hline Premix vitamínico ${ }^{1}$ (Vitamine premix) $^{-1}$ & 0,05 & 0,05 & 0,05 & 0,05 \\
\hline Premix mineral $^{2}$ (Mineral premix) & 0,12 & 0,12 & 0,12 & 0,12 \\
\hline Inerte (Inert) & 2,525 & - & - & - \\
\hline Bacitracina de zinco (Zinc bacitracine) & 0,015 & 0,015 & 0,015 & - \\
\hline Antioxidante (Antioxidant) (BHT) & 0,010 & 0,010 & 0,010 & 0,010 \\
\hline \multicolumn{5}{|c|}{ Composição calculada (Calculated composition) } \\
\hline Proteína bruta (Crude protein) $(\%)$ & 19,1 & 19,0 & 19,1 & 16,3 \\
\hline $\mathrm{ED}(E D) \mathrm{kcal} / \mathrm{kg}$ & 3408 & 3401 & 3400 & 3400 \\
\hline Cálcio (Calcium) (\%) & 0,95 & 0,91 & 0,91 & 0,92 \\
\hline Fósf. disp. (Available phosphorus) (\%) & 0,45 & 0,40 & 0,44 & 0,41 \\
\hline Lisina (Lysine) $(\%)$ & 1,25 & 1,25 & 1,25 & 0,80 \\
\hline Met + Cis $(M e t+C y s)(\%)$ & 0,80 & 0,66 & 0,70 & 0,55 \\
\hline Triptofano (Tryptophan) (\%) & 0,18 & 0,24 & 0,25 & 0,21 \\
\hline
\end{tabular}

${ }^{1}$ Conteúdo/kg (Containing/kg): vit. A, 9.000 .000 Ul; vit. $D_{3}, 900.000$ Ul; vit. E, 10.000 Ul; vit. $K_{3}, 4$ g; vit. $B_{1}, 2$ g; vit. $B_{2}, 5$ g; vit. $B_{6}, 5$ g; vit. $\mathrm{B}_{12}, 40 \mathrm{mg}$; ácido nicotínico (nicotinic acid), $40 \mathrm{~g}$; ácido pantotênico (pantothenic acid), $25 \mathrm{mg}$; selenito de sódio (selenium sodium), $50 \mathrm{mg}$; e veículo q.s.p., $1.000 \mathrm{~g}$.

2 Conteúdo/kg (Containing/kg): ferro (iron), $180 \mathrm{~g}$; cobre (copper), $20 \mathrm{~g}$; cobalto (cobalt), 4 g; manganês (manganese), $80 \mathrm{~g} ;$ zinco (zinc), 140 g; iodo (iodine), $4 \mathrm{~g}$; e veículo q.s.p., $1.000 \mathrm{~g}$.

\footnotetext{
R. Bras. Zootec., v.32, n.4, p.926-934, 2003
} 
a subseqüente, foram desprezadas outras 30 secções. Os corantes utilizados foram a hematoxilina e eosina. Para as análises morfométricas, foi utilizado o microscópio óptico OLYMPUS BX50 (aumento 40X) acoplado ao analisador de imagem "Image-Pro Plus 1.3.2" (1994). Foram selecionadas e medidas 30 vilosidades e 30 criptas, bem orientadas e seccionadas longitudinalmente. Observou-se também a integridade da mucosa, ocorrência e aspecto das Placas de Peyer.

Os dados foram submetidos à análise de variância utilizando-se o programa SAEG, desenvolvido na Universidade Federal de Viçosa -MG (UFV, 1997) e as médias comparadas pelo teste de Newman-Keuls, em nível de $5 \%$ de probabilidade. Para altura das vilosidades, da profundidade das criptas e da relação vilosidade:cripta, também foram observadas as curvas de regressão, em razão da idade ao abate.

\section{Resultados e Discussão}

Os resultados de pesos ao abate, pesos absolutos e relativos do fígado e do pâncreas e comprimentos absolutos e relativos do intestino delgado dos leitões aos 14, 21, 28 e 35 dias de idade, em razão das dietas experimentais, encontram-se na Tabela 2.

Os tratamentos influenciaram $(\mathrm{P}<0,05)$ os pesos relativo e absoluto do fígado e relativo do pâncreas somente aos 35 dias de idade. Os animais que consumiram a dieta CSFS tiveram órgãos mais leves. Não foi observada influência da dieta $(\mathrm{P}>0,05)$ sobre o peso absoluto do pâncreas e os comprimentos absoluto e relativo do intestino delgado.

Com relação ao peso absoluto do pâncreas, constatou-se que, apesar de não-significativo $(\mathrm{P}>0,05)$, o tratamento CSFS proporcionou aos animais pesos de pâncreas com valores variando de 32,2 a 37,6\%, menores que aqueles que receberam as dietas SMS, CCFS e SL, aos 35 dias de idade. Constatou-se que os valores dos órgãos foram baixos quando comparados aos de Pluske et al. (1996b) e Makkink et al. (1994a).

Observou-se que a dieta CSFS prejudicou o crescimento e aumento do peso dos órgãos digestivos, provavelmente devido à baixa ingestão de matéria seca, decorrente da inclusão do glúten de milho, informação que pode ter suporte nos dados de Mascarenhas et al. (1999), que, em experimento paralelo de desempenho, utilizando os mesmos tratamentos (Tabela 3), verificaram que a inclusão do glúten de milho em dietas reduziu o consumo e o ganho de peso dos leitões. Outro fator seria a ausên- cia do farelo de soja, que possui os antígenos glicinina e $\beta$-conglicinina, pois, segundo Makkink et al. (1994b) e Ferreira (1999), estes fatores demandam maior produção de enzimas pancreáticas, para a realização da digestão, interferindo no tamanho do órgão.

Os resultados de $\mathrm{pH}$ do conteúdo estomacal e intestinal de leitões aos 14, 21, 28 e 35 dias de idade, em razão das dietas experimentais, são apresentados na Tabela 4.

Não foi verificado efeito $(\mathrm{P}>0,05)$ das dietas sobre o pH do conteúdo estomacal e intestinal, nas idades analisadas. Observou-se que o $\mathrm{pH}$ da ingesta do estômago nas diferentes rações e idades está dentro da faixa ótima para atuação da pepsina ( 2 a 4) proposta por Passos Jr. (1997). Todavia, os valores de $\mathrm{pH}$ do intestino delgado foram baixos (5,68 a 6,23), quando comparados com o pH ideal para a ação da tripsina e quimotripsina $(7,8$ a 8,1), segundo Makkink et al. (1994a).

Segundo Lopes et al. (1986), o pH estomacal diminui com a idade e a hidrólise de proteína da soja começa a aumentar gradativamente, a partir dos 28 dias de idade; logo, pode-se deduzir que o aproveitamento de alimentos sólidos pelos leitões antes de 21 dias é reduzido em razão do baixo consumo e da pequena capacidade de hidrólise dos alimentos sólidos por estes animais.

Segundo Ferreira (1986), têm-se obtido resultados controversos entre os pesquisadores, com relação ao $\mathrm{pH}$ gastrintestinal, devido a uma série de fatores, tais como: a região onde foram feitas as determinações, o tipo de técnica usada para detectar $\mathrm{HCl}$ livre, o tempo após a ingestão do alimento, entre outros.

Os resultados de altura das vilosidades, profundidade das criptas e relação vilosidade:cripta do intestino delgado dos leitões, aos 14, 21, 28 e 35 dias de idade, em razão das regiões do intestino delgado, encontram-se apresentados na Tabela 5.

Não houve interação $(\mathrm{P}>0,05)$ entre a região do intestino delgado e as dietas experimentais. Também não houve diferença $(\mathrm{P}>0,05)$ entre as três regiões do intestino delgado de leitões, para todos parâmetros analisados, o que está de acordo com os estudos feitos por Abreu (1994) e Hampson (1986b).

Os resultados de altura das vilosidades (AV), profundidade das criptas (PC) e relação vilosidade:cripta (RVC) do intestino delgado dos leitões aos 14, 21, 28 e 35 dias de idade, encontram-se apresentados na Tabela 6 .

Não se observou efeito $(\mathrm{P}>0,05)$ das dietas experimentais sobre a AV e a RVC, nas idades analisa-

R. Bras. Zootec., v.32, n.4, p.926-934, 2003 
Tabela 2 - Peso médio ao abate, pesos absoluto e relativo do fígado e pâncreas e comprimento do intestino delgado de leitões aos 14, 21, 28 e 35 dias de idade, em razão das dietas experimentais

Table 2 - Weigh medium to the slaughter, weights absolute and relative of the liver and pancreas and length of the small intestine of pigs at the 14,21, 28 and 35 days of age, in reason of the experimental diets

\begin{tabular}{|c|c|c|c|c|c|}
\hline \multirow[t]{2}{*}{$\begin{array}{l}\text { Idade }(\mathrm{d}) \\
\text { Age }\end{array}$} & \multicolumn{4}{|c|}{$\begin{array}{l}\text { Dietas experimentais } \\
\text { Experimental diets }\end{array}$} & \multirow[t]{2}{*}{$\mathrm{CV}(\%)$} \\
\hline & CSFS & SMS & CCFS & SL & \\
\hline \multicolumn{6}{|c|}{ Peso médio abate $(\mathrm{g})$} \\
\hline 14 & 2450 & 2325 & 2600 & 2412 & 24,2 \\
\hline 21 & 4145 & 3640 & 3304 & 3593 & 19,5 \\
\hline 28 & 5090 & 5154 & 4851 & 5010 & 19,5 \\
\hline 35 & 5857 & 5227 & 6845 & 6397 & 18,2 \\
\hline \multicolumn{6}{|c|}{$\begin{array}{l}\text { Peso absoluto fígado }(\mathrm{g}) \\
\text { Absolute liver weight }\end{array}$} \\
\hline 14 & 91 & 89 & 99 & 91 & 24,2 \\
\hline 21 & 105 & 108 & 96 & 111 & 20,3 \\
\hline 28 & 135 & 149 & 148 & 157 & 15,5 \\
\hline 35 & $163 b$ & $192^{\mathrm{ab}}$ & $234^{\mathrm{a}}$ & $234^{\mathrm{a}}$ & 19,4 \\
\hline \multicolumn{6}{|c|}{$\begin{array}{l}\text { Peso relativo do fígado }(\%) \\
\text { Relative liver weight }\end{array}$} \\
\hline 14 & 3,75 & 3,83 & 3,95 & 3,82 & 17,5 \\
\hline 21 & 2,54 & 2,99 & 2,92 & 3,13 & 14,3 \\
\hline 28 & 2,66 & 3,00 & 3,09 & 3,16 & 10,5 \\
\hline 35 & $2,78 b$ & $3,81^{\mathrm{a}}$ & $3,41^{\mathrm{ab}}$ & $3,80^{\mathrm{a}}$ & 14,4 \\
\hline \multicolumn{6}{|c|}{$\begin{array}{l}\text { Peso absoluto do pâncreas }(\mathrm{g}) \\
\text { Absolute pancreas weight }\end{array}$} \\
\hline 14 & 2,26 & 2,78 & 2,65 & 2,29 & 48,7 \\
\hline 21 & 3,73 & 4,19 & 3,16 & 3,35 & 36,0 \\
\hline 28 & 5,48 & 7,32 & 6,79 & 7,26 & 32,4 \\
\hline 35 & 6,19 & 9,14 & 9,93 & 9,27 & 28,3 \\
\hline \multicolumn{6}{|c|}{$\begin{array}{l}\text { Peso relativo do pâncreas }(\%) \\
\text { Relative pancreas weight }\end{array}$} \\
\hline 14 & 0,10 & 0,12 & 0,11 & 0,09 & 44,6 \\
\hline 21 & 0,09 & 0,11 & 0,09 & 0,09 & 29,7 \\
\hline 28 & 0,11 & 0,13 & 0,14 & 0,14 & 25,9 \\
\hline 35 & $0,11 b$ & $0,17^{\mathrm{a}}$ & $0,14^{\mathrm{ab}}$ & $0,14^{\mathrm{ab}}$ & 26,0 \\
\hline \multicolumn{6}{|c|}{$\begin{array}{l}\text { Comprimento absoluto do intestino }(\mathrm{m}) \\
\text { Intestine absolute length }\end{array}$} \\
\hline 14 & 5,50 & 5,71 & 5,72 & 6,00 & 16,6 \\
\hline 21 & 6,74 & 6,49 & 6,61 & 7,21 & 10,6 \\
\hline 28 & 8,18 & 8,18 & 8,40 & 8,29 & 13,9 \\
\hline 35 & 10,24 & 9,34 & 10,15 & 10,53 & 12,7 \\
\hline \multicolumn{6}{|c|}{$\begin{array}{l}\text { Comprimento relativo do intestino }(\mathrm{m} / \mathrm{kg}) \\
\text { Intestine relative length }\end{array}$} \\
\hline 14 & 2,48 & 2,53 & 2,37 & 2,53 & 18,5 \\
\hline 21 & 1,66 & 1,87 & 2,03 & 2,04 & 16,2 \\
\hline 28 & 1,69 & 1,77 & 1,75 & 1,67 & 16,4 \\
\hline 35 & 1,77 & 1,85 & 1,52 & 1,77 & 23,2 \\
\hline
\end{tabular}

Médias, na mesma linha, seguidas de letras diferentes diferem pelo teste Newman-Keuls $(P<0,05)$.

Means, within a row, followed different letters are different $(P<.05)$ by Newman-Keuls test.

das. Todavia, aos 21 e 35 dias de idade, observou-se efeito $(\mathrm{P}<0,05)$ das dietas sobre a $\mathrm{PC}$, sendo que os animais que consumiram as dietas SL e CCFS apresentaram criptas mais profundas, aos 21 e 35 dias de idade, respectivamente. Observaram-se criptas $21,8 \%$ mais profundas nos animais que consumiram a dieta CCFS em relação à dieta CSFS.
Os resultados desta pesquisa diferem dos encontrados por Berto et al. (1996), que não observaram efeito de dietas simples ou complexa sobre a morfologia intestinal de leitões desmamados aos 28 dias de idade.

Aumento na PC é compatível com incremento na produção de células e, sobretudo, a um estímulo na

\footnotetext{
R. Bras. Zootec., v.32, n.4, p.926-934, 2003
} 
Tabela 3 - Ganho de peso (GPD), consumo médio diário (CMD) e conversão alimentar (CA) dos leitões dos 21 aos 35 dias de idade, em função das dietas ${ }^{1}$

Table 3 - Average daily feed intake (ADFI), daily weight gain (ADG) and feed:gain ratio (F/G) of piglet from 21 to 42 days of age, in function of the diet

\begin{tabular}{|c|c|c|c|c|c|}
\hline \multirow[t]{2}{*}{$\begin{array}{l}\text { Parâmetros } \\
\text { Parameters }\end{array}$} & \multicolumn{4}{|c|}{$\begin{array}{l}\text { Dietas experimentais } \\
\text { Experimental diets }^{2}\end{array}$} & \multirow[t]{2}{*}{$\mathrm{CV}$} \\
\hline & CSFS & SMS & CCFS & SL & \\
\hline$\overline{\mathrm{GPD}}(\mathrm{g} / \mathrm{dia}) A D G(\mathrm{~g} /$ day $)$ & $52^{\mathrm{c}}$ & $118^{\mathrm{a}}$ & $118^{\mathrm{a}}$ & $99^{\mathrm{b}}$ & 14,46 \\
\hline $\mathrm{CMD}$ (g/dia) ADFI (g/day) & $127^{\mathrm{b}}$ & $190^{\mathrm{a}}$ & $198^{\mathrm{a}}$ & $182^{\mathrm{a}}$ & 12,77 \\
\hline $\mathrm{CA} \mathrm{F/G}$ & $2,46^{\mathrm{a}}$ & $1,62^{b}$ & $1,67^{b}$ & $1,84^{\mathrm{a}}$ & 10,49 \\
\hline
\end{tabular}

${ }_{1}^{1}$ Adaptado de Mascarenhas et al. (1999) (Adapted of Mascarenhas et al., 1999)

${ }^{2}$ Médias, na linha, seguidas de letras diferentes são diferentes $(P<0,05)$ (Means, within a row, follwed by different letters are different $(P<.05)$

Tabela 4 - pH da ingesta estomacal e da digesta intestinal, em razão das dietas experimentais e da idade ao abate dos leitões

Table 4 - $\mathrm{pH}$ stomach contents and of the contents intestine, in reason of experimental diets and of age to slaughter the pigs

\begin{tabular}{|c|c|c|c|c|c|}
\hline \multirow[t]{2}{*}{$\begin{array}{l}\text { Idade }(\mathrm{d}) \\
\text { Age }\end{array}$} & \multicolumn{4}{|c|}{$\begin{array}{c}\text { Dietas experimentais } \\
\text { Experimental diets }\end{array}$} & \multirow[t]{2}{*}{$\mathrm{CV}(\%)$} \\
\hline & CSFS & SMS & CCFS & SL & \\
\hline \multicolumn{6}{|c|}{$\begin{array}{c}\mathrm{pH} \text { estomacal } \\
\text { pH estomach }\end{array}$} \\
\hline 14 & 3,73 & 3,50 & 3,53 & 3,63 & 10,9 \\
\hline 21 & 2,70 & 4,40 & 3,99 & 3,84 & 30,2 \\
\hline 28 & 3,51 & 3,71 & 2,97 & 4,39 & 27,2 \\
\hline 35 & 3,52 & 2,33 & 2,92 & 2,70 & 31,3 \\
\hline \multicolumn{6}{|c|}{$\begin{array}{l}\mathrm{pH} \text { intestinal } \\
\text { pH intestine }\end{array}$} \\
\hline 14 & 6,13 & 6,11 & 5,92 & 5,78 & 6,7 \\
\hline 21 & 6,16 & 6,22 & 6,23 & 5,90 & 5,9 \\
\hline 28 & 5,86 & 5,78 & 5,68 & 5,97 & 6,2 \\
\hline 35 & 5,97 & 5,96 & 5,71 & 6,01 & 8,0 \\
\hline
\end{tabular}

renovação das células do intestino delgado, e, segundo Pluske et al. (1996a), a PC e a AV está mais relacionado com o consumo de alimento do que algum efeito antigênico da dieta. Logo, criptas mais profundas aos 21 dias de idade podem estar relacionada com a diferença no consumo de leite da porca. Já aos 35 dias de idade, Mascarenhas et al. (1999), no experimento de desempenho (Tabela 3), observaram $64,2 \%$ a mais de consumo da dieta CCFS, em relação à dieta CSFS.

Observou-se efeito quadrático $(\mathrm{P}<0,01)$ para altura das vilosidades (Figura 1), efeito linear $(\mathrm{P}<0,01)$ para profundidade das criptas (Figura 2) e efeito quadrático $(\mathrm{P}<0,01)$ para relação vilosidade:cripta (Figura 3), em razão das idades de abate dos animais.

Aumento da PC em função da idade e redução da $\mathrm{AV}$ e RVC do $14^{\circ}$ ao $27^{\circ}$ e e $14^{\circ}$ a ao $30^{\circ}$ o dia de idade, respectivamente, foram observados. $\mathrm{O}$ aumento da $\mathrm{PC}$, principalmente após o desmame, e a tendência de recuperação da AV e RVC aos 35 dias de idade estão de acordo com Abreu (1994), Cera et al. (1988), Hoppe et al. (1990), Hampson (1986ab) e Miller et al. (1986). Entretanto, não se verificou diminuição drástica da altura das vilosidades com o desmame.

Segundo estes pesquisadores, as vilosidades são maiores no recém-nascido e diminuem gradualmente com a idade, apesar de os leitões ainda estarem mamando. A maior redução ocorre por ocasião do desmame, que pode estar relacionada diretamente com o período durante o qual o leitão, diminui o consumo de matéria seca, com reflexos diretos na taxa de crescimento.

Em revisão, Nabuurs (1995) concluiu que a suplementação de ração durante o período de amamentação é benéfica para prevenir o encurtamento das vilosidades. Teodoro et al. (1998) verificaram que o consumo e a composição da dieta pré e pósdesmame favorecem a produção de enzimas digestiva 
Tabela 5 - Altura das vilosidades, profundidade das criptas e relação vilosidade:cripta em razão das regiões do intestino delgado de leitões, aos 14,2128 e 35 dias de idade

Table 5 - Villous height, crypt depth and villousi:cripta relation, according to the region of small intestine of pigs at 14, 21, 28 and 35 days of age

\begin{tabular}{|c|c|c|c|c|}
\hline \multirow{3}{*}{$\begin{array}{l}\text { Idade (Dias } \\
\text { Day of age }\end{array}$} & \multirow{2}{*}{\multicolumn{3}{|c|}{$\begin{array}{l}\text { Regiões }(\%) \\
\text { Region }\end{array}$}} & \multirow[t]{3}{*}{$\mathrm{CV}(\%)$} \\
\hline & & & & \\
\hline & 25 & 50 & 75 & \\
\hline \multicolumn{5}{|c|}{ Altura das vilosidades $(\mu \mathrm{m})$} \\
\hline \multicolumn{5}{|c|}{ Villous height } \\
\hline 14 & 476 & 517 & 450 & 22,4 \\
\hline 21 & 341 & 325 & 313 & 19,9 \\
\hline 28 & 338 & 349 & 341 & 13,9 \\
\hline 35 & 338 & 359 & 363 & 15,1 \\
\hline \multirow{2}{*}{\multicolumn{5}{|c|}{$\begin{array}{l}\text { Profundidade das criptas }(\mu \mathrm{m}) \\
\text { Crypt depth }\end{array}$}} \\
\hline & & & & \\
\hline 14 & 173 & 167 & 168 & 15,4 \\
\hline 21 & 191 & 202 & 192 & 11,4 \\
\hline 28 & 252 & 263 & 250 & 10,5 \\
\hline 35 & 282 & 275 & 261 & 11,5 \\
\hline \multicolumn{5}{|c|}{$\begin{array}{l}\text { Relação vilosidade:cripta } \\
\text { Villous:cripta relation }\end{array}$} \\
\hline 14 & 2,75 & 3,09 & 2,68 & 29,1 \\
\hline 21 & 1,78 & 1,60 & 1,63 & 22,6 \\
\hline 28 & 1,35 & 1,33 & 1,37 & 15,7 \\
\hline 35 & 1,20 & 1,31 & 1,39 & 20,1 \\
\hline
\end{tabular}

e a proliferação das células do epitélio intestinal, por meio de efeito trófico, impedindo a diminuição na altura das vilosidades após o desmame.

Os valores de AV obtidos neste trabalho estão abaixo dos achados de Abreu (1994), que, trabalhando no mesmo rebanho, encontrou vilosidades com, aproximadamente, $720,570,390$ e $470 \mu \mathrm{m}$ de altura, respectivamente, aos $14,21,28$ e 35 dias de idades, nas mesmas regiões do intestino delgado, o que, segundo Pluske et al. (1997), pode ser atribuído a fatores como temperatura, sanidade ou manejo da maternidade.

O fornecimento de dieta contendo de 17 a $29 \%$ de farelo de soja no pré-desmame também pode ter contribuído para o desenvolvimento de tolerância aos antígenos (glicinina e ß conglicinina), evitando menor diminuição da altura das vilosidades pós-desmame (Li et al., 1990; Abreu, 1994). Por outro lado, Dunsford et al. (1989) observaram alterações morfológicas no intestino delgado de leitões, em razão de altas concentrações de farelo de soja nas dietas iniciais.

Nas análises qualitativas dos fragmentos intestinais, contatou-se que as células caliciformes estão

Tabela 6 -Altura das vilosidades, profundidade das criptas e relação vilosidade:cripta do intestino delgado de leitões, aos 14, 2128 e 35 dias de idade, em razão das dietas experimentais

Table 6 - Villous height, crypt depth and villous:cripta relation of small intestine of pigs at 14, 21, 28 and 35 days of age, according to the experimental diets

\begin{tabular}{|c|c|c|c|c|c|c|}
\hline \multirow[t]{2}{*}{$\begin{array}{l}\text { Idade }(\mathrm{d}) \\
\text { Age }\end{array}$} & \multicolumn{4}{|c|}{$\begin{array}{l}\text { Dietas experimentais } \\
\text { Experimental diets }\end{array}$} & \multirow[t]{2}{*}{$\begin{array}{l}\text { Médias } \\
\text { Means }\end{array}$} & \multirow[t]{2}{*}{$\mathrm{CV}(\%)$} \\
\hline & CSFS & SMS & CCFS & SL & & \\
\hline \multicolumn{7}{|c|}{ Altura das vilosidades $(\mu \mathrm{m}) \mathrm{CV}(\%)$} \\
\hline 14 & 476 & 487 & 477 & 483 & 481 & 13,9 \\
\hline 21 & 338 & 338 & 331 & 328 & 334 & 9,4 \\
\hline 28 & 308 & 339 & 330 & 347 & 331 & 15,3 \\
\hline 35 & 359 & 357 & 342 & 354 & 353 & 12,4 \\
\hline \multicolumn{7}{|c|}{$\begin{array}{l}\text { Profundidade das criptas }(\mu \mathrm{m}) \\
\text { Crypt depth }\end{array}$} \\
\hline 14 & 170 & 175 & 168 & 164 & 169 & 13,9 \\
\hline 21 & $187 \mathrm{~b}$ & $188 \mathrm{~b}$ & $197 b$ & $217 \mathrm{a}$ & 197 & 6,9 \\
\hline 28 & 242 & 258 & 259 & 260 & 255 & 9,1 \\
\hline 35 & $252 \mathrm{~b}$ & $272 b$ & $307 \mathrm{a}$ & $259 \mathrm{~b}$ & 272 & 6,8 \\
\hline \multicolumn{7}{|c|}{ Relação vilosidade:cripta } \\
\hline & & Villou & onship & & & \\
\hline 14 & 2,80 & 2,78 & 2,83 & 2,94 & 2,83 & 24,9 \\
\hline 21 & 1,82 & 1,80 & 1,68 & 1,51 & 1,70 & 16,8 \\
\hline 28 & 1,27 & 1,31 & 1,27 & 1,34 & 1,29 & 8,6 \\
\hline 35 & 1,43 & 1,31 & 1,12 & 1,37 & 1,31 & 15,7 \\
\hline
\end{tabular}

Médias, na mesma linha, seguidas de letras diferentes diferem pelo teste Newman-Keuls $(\mathrm{P}<0,05)$.

Means, within a row, followed different letters are different $(P<.05)$ by Newman-Keuls test. 


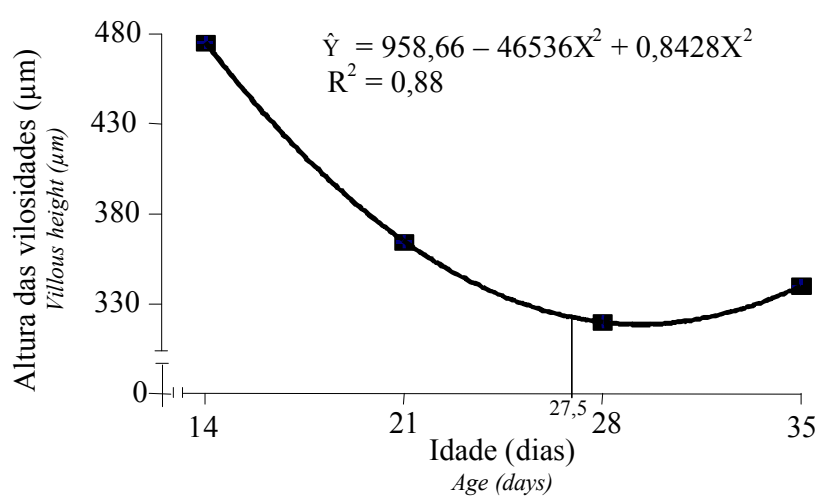

Figura 1 - Altura das vilosidades do intestino delgado, em função das idades ao abate dos leitões.

Figure 1 - Villous height of small intestine, according to the pigs age at slaughter.

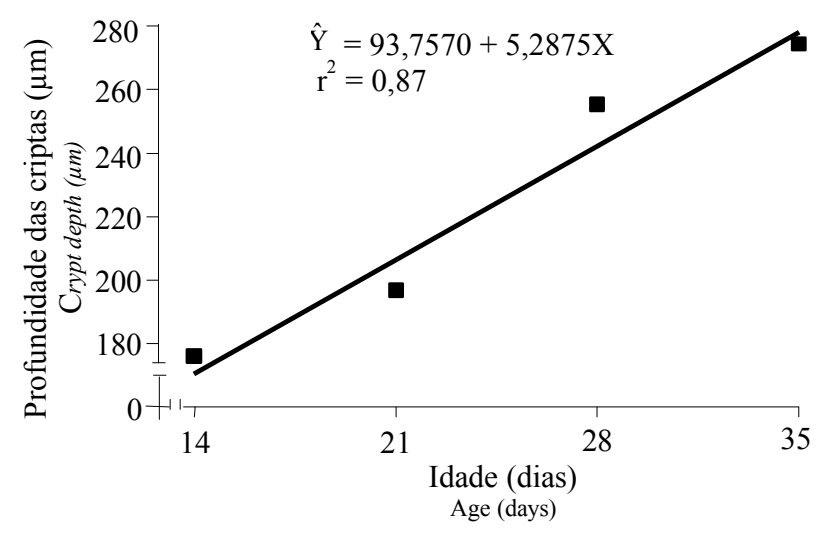

Figura 2 - Profundidade das criptas do intestino delgado, em função das idades ao abate dos leitões.

Figure 2 - Crypt depth of small intestine, according to the pigs age at slaughter.

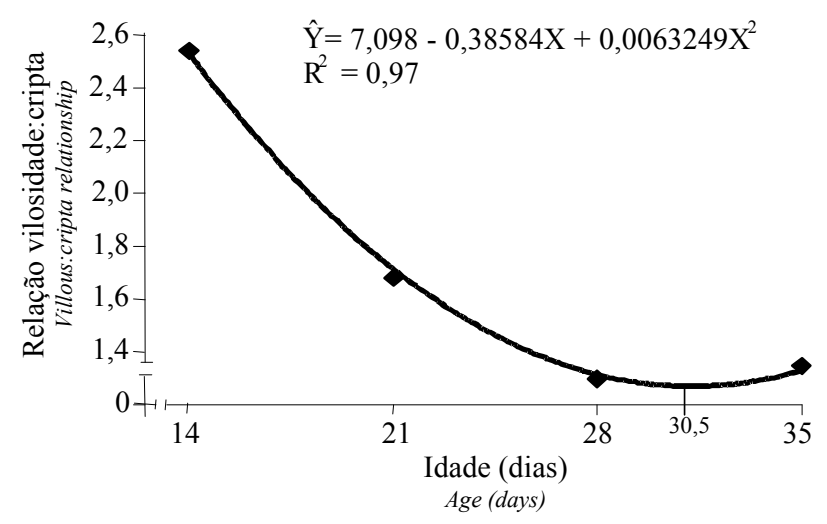

Figura 3 - Relação vilosidade:cripta do intestino delgado, em função das idades ao abate dos leitões.

Figure 3 - Villous:cripta relationship of small intestine, according to the pigs age at slaughter. localizadas preferencialmente nas criptas e na base das vilosidades. Não foram observadas descamações e mudança na forma das células epiteliais, em função dos tratamentos. Entretanto, no tratamento CSFS, as Placas de Peyer foram verificadas em todas as regiões, em maior número e tamanho.

Segundo Vega López \& Stokes (1994), o tamanho das placas de Peyer pode ser determinado pela idade e pelo conteúdo microbiano do intestino, porém o número e a posição das placas individuais permanecem constantes.

\section{Conclusões}

O tipo de dieta, seja simples ou complexa, em razão da qualidade e quantidade dos ingredientes, afetou a profundidade das criptas do intestino delgado e o peso dos órgãos auxiliares da digestão, mas não influenciou o $\mathrm{pH}$ do conteúdo estomacal e intestinal de leitões desmamados aos 21 dias de idade.

\section{Literatura Citada}

ABREU, M.L.T. Efeito da proteína do farelo de soja sobre o desempenho e ocorrência de alterações digestivas em leitões desmamados aos 21 dias de idade. Viçosa, MG: Universidade Federal de Viçosa, 1994. 79p. Dissertação (Mestrado em Zootecnia) - Universidade Federal de Viçosa, 1994.

BERTO, D.A.; KRONKA, R.N.; SANTOS, H.S.L. et al. Efeito do tipo de ração inicial sobre a morfologia intestinal e digestibilidade dos nutrientes em leitões. Revista Brasileira de Zootecnia, v.25, n.5, p.973-86, 1996.

BERTO, D.A.; KRONKA, R.N.; THOMAZ, M.C. et al. Efeito do tipo de dieta e do sistema de alimentação sobre o desempenho de leitões. Revista Brasileira de Zootecnia, v.26, n.1, p.144-152, 1997.

BERTOL, T.M.; MORAES, N.; FRANKE, M.R. Substituição do farelo de soja por soja integral extrusada na dieta de leitões recentemente desmamados. In: CONGRESSO BRASILEIRO DE VETERINÁRIOS ESPECIALISTAS EM SUÍNOS, 8.,1997, Foz do Iguaçu. Anais... Foz do Iguaçu: ABRAVES, 1997a. p.351-352.

BERTOL, T.M.; MORAES, N.; FRANKE, M.R. Substituição do farelo de soja por proteína texturizada de soja na dieta de leitões desmamados aos 21 dias de idade. In: CONGRESSO BRASILEIRO DE VETERINÁRIOS ESPECIALISTAS EM SUÍNOS, 8., 1997, Foz do Iguaçu. Anais... Foz do Iguaçu: ABRAVES, 1997b. p.353-354.

CERA, K.R.; MAHAN, D.C.; CROOS, R.F. et al. Effect of age, weaning and postweaning diet on small intestinal growth and jejunal morphology in young swine. Journal of Animal Science, v.66, n.5, p.74-84, 1988.

DUNSFORD, B.R.; KNABE, D.A.; HAENSLY, W.E. Effect of dietary soybean meal on the microscopic anatomy of the small intestine in the early-weaned pig. Journal of Animal Science, v.67, n.7, p.1855-63, 1989.

R. Bras. Zootec., v.32, n.4, p.926-934, 2003 
FERREIRA, A.S. Estimativa de produção e composição de leite de porca e aleitamento artificial de leitões. Viçosa, MG: Universidade Federal de Viçosa, 1986. 121p. Tese (Doutorado em Nutrição de Monogástrico) - Universidade Federal de Viçosa, 1986.

FERREIRA, V.P A. Dietas para leitões em aleitamento e pós desmame. Viçosa, MG: Universidade Federal de Viçosa, 1999. 40p. Dissertação (Mestrado em Zootecnia) - Universidade Federal de Viçosa, 1999.

HALL, G.A.; BYRNE, T.F. Effects of age and diet on small intestinal structure and function in gnonotobiotic piglets. Research in Veterinary Science, v.47, p.387-392, 1989.

HAMPSON, D.J. Alterations in piglet small intestinal structure at weaning. Research in Veterinary Science, v.40, p32-40, 1986a.

HAMPSON, D.J. Attempts to modify changes in the piglets small intestinal after weaning. Research in Veterinary Science, v.40, p313, 1986b.

HOPPE, M.K.; LiBAL, G.W.; HAMILTON, C.R. et al. Effect of postweaning feed intake on weaning pig intestinal morfhology. Journal of Animal Science, v.68, p.392, 1990.

IMAGE - PRO PLUS 1.3.2. The Proven Solution for Image Analysis. Reference Guide, 1994.

JIN, L.; REYNOLDS, L.P.; REDMER, J.S. et al. Efects of dietary fiber on intestinal growth, cell prolliferation and morfology in growing pigs. Journal of Animal Science, v.72, p.22702278, 1994.

LI, D.F.; NELSSEN, J.L.; REDDY, P.G. et al. Transient hipersensitivity to soybean meal in the early-weaned pig. Jornal Animal Science, v.68, n.6, p.1790-1799, 1990.

LOPES, D.C.; DONZELE, J.L.; ALVARENGA, J.C. et al. Avaliação de épocas do início do arraçoamento de leitões em aleitamento. Revista Brasileira de Zootecnia, v.15, n.3, p.219-223, 1986.

MAKKINK, C.A.; BERNTSEN, P.J.M.; KAMP, B.M.L. et al. Gastric protein breakdown and pancreatic enzyme activities in response to different dietary protein sources in newly weaned pigs. Journal Animal Science, v.72, p.2843-2850, 1994a.

MAKKINK, C.A.; NEGULESCU, G.P.; GUIXIN, Q. et al. Effect of dietary protein source on feed intake, growth, pancreatic enzyme activities and jejunal morphology in newly-weaned piglets British Journal of Nutrition, v.72, p.353-368, 1994b.

MANNERS, J.H.; POND, M.C.; LOOSLI, M.C. et al. Effect of isolated soybean protein and casein on the gastric $\mathrm{pH}$ and of passage of food residues on baby pigs. Journal of Animal Science, v.21, p.49-55, 1962.

MASCARENHAS, A.G.; FERREIRA, A.S.; DONZELE, J.L. et al. Avaliação de dietas fornecidas dos 14 aos 42 dias de idade sobre o desempenho e a composição de carcaça de leitões. Revista Brasileira de Zootecnia, v.28, n.6, p.1319-1326, 1999.

MILLER, B.G.; JAMES, P.S.; SMITH, M.W. et al. Effect of weaning on the capacity of pig intestinal villi to digest and absorb nutrients. Journal of Agriculture Science, v.107, p.579-85, 1986.

MOON, H.M. Epithelial cell migration in the migration of the suckling pig. Proceedings of the Society for Experimental Biology and Medicine, v.137, p.151-154, 1971.

NABUURS, M.J.A. Microbiological, strutural and functional changes of the small intestine of pigs at weaning. Pigs New and Information, v.16, n.3, p.93N-97N, 1995.

NELSSEN, J.L.; DRITZ, S.S.; TOKACH, M.D. et al. Nutritional programs for early-weaned pigs. In: CONGRESSO BRASILEIRO DE VETERINÁRIOS ESPECIALISTAS EM SUÍNOS, 8., 1997, Foz do Iguaçu. Anais... Foz do Iguaçu: ABRAVES, 1997. p.126-136.

PASSOS JR., H.S. Nutrição e meio ambiente para leitões em sistema de produção com desmame precoce segregado. In: CONGRESSO BRASILEIRO DE VETERINÁRIOS ESPECIALISTAS EM SUÍNOS, 8.,1997, Foz do Iguaçu. Anais... Foz do Iguaçu: ABRAVES, 1997. p.41-54.

PLUSKE, J.R.; WILLIAMS, I.H.; AHERNE, F.X. Nutrition of neonatal pig: development and surviral. London: CAB International, 1995. p.187-235.

PLUSKE, J.R.; WILLIAMS, I.H.; AHERNE, F.X. Maintenence of villous height and crypt depth by providing continuous nutrition after weaning. Animal Science, v.62, p.131-144, 1996a.

PLUSKE, J.R.; WILLIAMS, I.H.; AHERNE, F.X. Villous height and crypt depth in piglets in response to increases in intake of cow's milk after weaning. Animal Science, v.62, p.145$158,1996 \mathrm{~b}$.

PLUSKE, J.R.; HAMPSON, D.J.; WILLIAMS, I.H. Factors influencing the structure and function of the small intestine in the weaned pig: a review. Livestock Production Science, v.51, p.215-236, 1997.

ROSTAGNO, H.S.; SILVA, D.J.; COSTA, P.M.A. et al. Composição de alimentos e exigências nutricionais de aves e suínos (tabelas brasileiras). Viçosa, MG: Universidade Federal de Viçosa, 1992. 79p.

TEODORO, M.T.; BERTO, D.A.; PAI, V.D. et al. Estrutura intestinal de leitões desmamados precocemente, alimentados com dietas farelada ou extrusada seca e úmida. In: REUNIÃO ANUAL DA SOCIEDADE BRASILEIRA DE ZOOTECNIA, 35., 1998, Botucatu. Anais... Botucatu: Sociedade Brasileira de Zootecnia, 1998. v.4, p.343-344.

THOMAZ, M.C., OLIVEIRA, A.C.,ONKA, R.N. et al. Diferentes fontes protéicas e épocas de abate sobre a ultraestrutura do duodeno de leitões desmamados. In: REUNIÃO ANUAL DA SOCIEDADE BRASILEIRA DE ZOOTECNIA, 33., Fortaleza. Anais... Fortaleza: Sociedade Brasileira de Zootecnia, 1996. v.1, p.108-109.

UNIVERSIDADE FEDERAL DE VIÇOSA - UFV. S.A.E.G. (Sistema de Análise Estatísticas e Genéticas). Viçosa, MG, 1997. (Versão 7.1).

VEGA-LÓPEZ, M.A.; STOKES, C.R. Desarrollo del sistema inmune intestinal porcino. Tecnica Pecuaria en Mexico, v.32, n.1, p.30-38, 1994.

WILSON, R.H.; LEIBHOLZ, J. Digestion in the pig between 7 and $35 \mathrm{~d}$ of age. 2 . The digestion of dry matter and $\mathrm{pH}$ of digesta in pigs given milk and soya-bean proteins. British Journal of Nutrition, v.45, n.2, p.321-336, 1981. 